\section{UK centres target brain drain}

London. Getting British-trained molecular biologists and researchers in related disciplines to return after postdoctoral experience in Europe and the United States is a priority for the directors of two new interdisciplinary centres being set up by the University of London.

"Some people are not coming back because the mid-range jobs have dried up, but now even the best people are not coming back", says Nigel Holder, director of the Developmental Biology Research Centre (DBRC), which was opened last week at King's College London. Holder-said that one of the criteria by which he will judge the success of the DBRC is by how many people can be lured home from overseas.

The conditions keeping postdoctoral researchers from returning are also making it difficult for those who have stayed behind. Small, interdisciplinary research centres such as the DBRC and the Laboratory of Molecular Cell Biology (LMCB), due to open at University College London in May 1993, are increasingly being seen as one of the few ways to conduct research of internationalquality in a university setting.

In opening the DBRC, Sir Mark Richmond, chairman of the Science and Engineering Research Council (SERC), said that too much research in universities is being forced into classical scientific disciplines to match teaching patterns, a situation that is out of touch with the cutting edge of science. "If you are having to talk about interdisciplinary work, that means you have got the definition of the discipline wrong", he said.

Although most of the researchers staffing the DBRC and the LMCB will have departmental posts, the centres themselves are outside the departmental system. The DBRC has 45 research positions spread through ten laboratories, supported by $£ 3.5$ million (US\$6.7 million) from research council and charity project grants. Core funding for the building has come from King's College. Two of the group leader posts have been funded externally as fiveyear contracts with the Medical Research Council (MRC) and the SERC, and both have been filled by the sort of candidates that Holder was hoping to attract.

The LMCB, with plans for between 70 and 90 researchers, also plans to use five-

\section{Correction}

Professor Luc Montagnier says that, contrary to the statement in Nature $(358,6 ; 1992)$, he was not an adviser to the French government in 1983-85. However, as early as August 1983, Montagnier did warn government officials that production facilities for HIV (then LAV) were urgently needed for blood testing. - Editor, Nature. year contracts under a fellowship scheme to attract postdoctoral students who have stayed abroad. The response so far has been encouraging. "What surprised us was that it was not just people who had just finished postdoc positions who applied, but also people who had been in the US for ten or so years, waiting for a chance to come back," said Colin Hopkins, director of the LMCB. "They appear to be willing to take a cut in status, if not a cut in salary, in order to return to this country."

The LMCB differs from the DBRC in that it is funded under a government scheme for interdisciplinary research centres. It has been built and equipped by the MRC, with the work to be funded by project grants. The LMCB also incorporates an institute whose membership will give like-minded researchers on other campuses access to LMCB facilities and encourage interchange within the molecular biology community. There are also plans to develop a graduate school in molecular biology.

Although developing this sort of research centre is not an option for every British university, there is a feeling that Britain can accommodate several in each field. In molecular biology alone, Hopkins feels that there is room for six or eight centres.

The centres also provide a way for the SERC to exercise greater control over what its researchers do and how they divide their time between teaching and research. The MRC works largely through its own units in universities and hospitals, where its researchers are essentially full-time employees. Similarly, the Agriculture and Food Research Council and the Natural Environment Research Council have institutes devoted to particular areas of research. Most of the recipients of SERC grants, however, work in university department laboratories and face increasing demands to teach.

There are expected to be 300,000 more students in the British university system by 2000 , and the bodies governing higher education are devising a plan to accommodate them. The most important changes are likely to involve the idea of extending the length of the teaching day and week and adding a summer term. "If researchers are not protected from these things, when on earth are they going to do research?" asks Richmond.

Starting this autumn, the SERC will become responsible for funding all the direct costs of its research. In the past, those costs were shared with the Universities Funding Council. If the SERC is not convinced that the laboratories of its grant recipients are going to have the full support of the host university, Richmond says, then it may want to consider funding its own institutions. Making his position clear, Richmond said "that is a direction I am absolutely opposed to."

Ian Mundell

\section{Concrete holds key to ESRF's opening}

London. Construction engineers at the European Synchrotron Radiation Facility (ESRF) in Grenoble, France, are monitoring an expanse of concrete slabs to see if they have remedied a construction problem that could delay the start of experiments and reduce the number of beam lines for researchers.

The error came to light last December, when the floor of the experimental hall was found to be curling. Engineers believe that the concrete slabs making up the floor of the facility were not entirely set, and when exposed to air the tops dried faster than the bottoms.

The problem has been solved by injecting more concrete under the slabs, according to Ruprecht Haensel, ESRF's director general. Only a third of the experimental hall - the minimum required to start the beam-line programme - has so far been treated, leaving it stable if not entirely level. The synchrotron itself has not had the same problems and is already producing 'light'.

Engineers are monitoring the floor to determine the durability of the repairs. The situation is complicated by the fact that the instruments to be installed may be more sensitive than those envisaged when the project was started in 1987.

ESRF officials profess optimism. "The problem has not been negligible, but by no means has it endangered any of the dates for user operations," Haensel says about the project, which technically was six months ahead of schedule when the problem was discovered. But in private there remains talk about tearing up the floor and starting again.

Ian Mundell

\section{Chinese researchers promised more}

Beijing. Prominent Chinese researchers last month heard their government's finance minister promise them more money - sometime. At a meeting on 17 June between Wang Bing-Ojan and the Chinese Academy of Sciences, the finance minister said that the government has adopted a policy, to be implemented next year, "of gradually leaning towards more scientific research funds".

The academy has worked hard to convince Wang and other top government officials of the need for additional funding of science. Zhou Guang-Zhao, president of the academy, led Wang on a tour of the academy's chemistry, computation and biophysics institutes, and afterwards Wang spoke of the talented research staff and potential for rapid progress. In the interim, Wang encouraged his audience to look for support from international organizations such as the World Bank.

You Qin Li 